Ruiz, C., Tito, C., and Paredes, M. 2020. "Effects of Implementation of 5S in Heavy Equipment Maintenance Workshops." In: Tommelein, I.D. and Daniel, E.I. (eds.). Proc. $28^{\text {th }}$ Annual Conference of the International Group for Lean Construction (IGLC28), Berkeley, California, USA, doi.org/10.24928/2020/0010, online at iglc.net.

\title{
EFFECTS OF IMPLEMENTATION OF 5S IN HEAVY EQUIPMENT MAINTENANCE WORKSHOPS
}

\author{
Cristina Ruiz ${ }^{1}$, Tito Castillo ${ }^{2}$, and Marcel Paredes ${ }^{3}$
}

\begin{abstract}
The intensive use of heavy equipment is the production core of a road construction company, so maintenance is critical activity to ensure its availability. However, conventional maintenance techniques usually compromise the work safety of personnel by pressing their work capacity, although these maintenance processes can be managed applying methodologies that achieve clean, safe and organized workspaces. Thus, the purpose of this research was to measure the effects of the $5 \mathrm{~S}$ implementation in the maintenance workshop of a road construction company.

For such purpose, were used indicators of equipment availability, occupational safety and efficiency. Having the support of senior management, training and application of $5 \mathrm{~S}$ were carried out on site. Unnecessary supplies and those of frequent use by the worker were classified (Seiri). Shelves coded for storage were created (Seiton). Parts were removed of scrap and debris from work areas (Seiso). Also, order and cleaning procedures were standardized (Seiketsu). Finally, through visual tools, self-discipline was promoted (Shitsuke). Although the application of 5S did not significantly improve the equipment availability indicators of the workshop, its implementation reduced the accident index and improved working conditions.
\end{abstract}

\section{KEYWORDS}

5S, standardization, visual management, efficiency, safety

\section{INTRODUCTION}

In 1992, Koskela adapted the application of Lean production systems to the construction industry (Pons 2014), proving that their use reduces material in stock, time and unnecessary effort, also generates maximum value and job security for a construction company (Porras et al. 2014). One of these tools is the 5S order and cleaning principle, applied to any workplace like shops, services, manufacturing, warehouses and offices (Sowards 2012). Also has been applied in infrastructure projects through the daily

1 Civil Engineer, Faculty of Engrg., Universidad Nacional de Chimborazo (UNACH), Av. Antonio José de Sucre Km 1 1/2 vía a Guano Riobamba, Ecuador, jcruiz.fic@unach.edu.ec, orcid.org/0000-00024048-7939

2 Prof., Civil Engrg. Dept., Director, Universidad Nacional de Chimborazo (UNACH), Av. Antonio José de Sucre Km 11/2 vía a Guano Riobamba, Ecuador, tcastillo@unach.edu.ec, orcid.org/0000-0002$\underline{3472-3456}$

3 Prof., Civil Engrg., Faculty of Engrg., Universidad Nacional de Chimborazo (UNACH), Av. Antonio José de Sucre Km 1 1/2 vía a Guano Riobamba, Ecuador, marcelparedes@unach.edu.ec, orcid.org/0000- 0002-3762-9633 
management of civil works with standardized processes. However, in heavy machinery maintenance workshops, the versatility of the methodology was still inconceivable (Espuny 2009). Most road builders appoint managers who are knowledgeable of the development of machinery on site to make decisions and carry out technical work related to the procurement, availability and replacement of mechanical parts, which makes Machinery maintenance management practices are an ambiguous process, which is not enough. Being the automotive company Toyota, a pioneer in the application of $5 \mathrm{~S}$ that leads the standards of competitiveness within the market by leaning on management techniques derived from the Lean Production philosophy and thus guaranteeing the timely delivery of vehicles to its customers.

However, a staff that tends to resist change, rancid work habits and the risk of investment losses are some of the reasons that prevent a wider implementation of $5 \mathrm{~S}$ in construction companies (Salem et al. 2015). 5S implementation needs adequate indicators that allow to know the progress of the system, using organizational change management methodologies (Burnes 2004), and assigning roles to the worker, who is the fundamental entity, the only recipient and producer of change and innovation (Boatswain 2016).

Worldwide, the application of Lean methodologies has reached construction companies high standards of competitiveness in the market by creating adequate facilities and reducing the variability of processes (Pestana and Gambatese 2016; Porras et al. 2014). Specially, 5S techniques lead to improved productivity by involving employees, ensuring tools and equipment availability and improving material flow (Sowards 2012). However, Lean Construction techniques has been scarcely implemented in Ecuadorian construction companies' despite of their low productivity related to production variability and inconveniences in availability of construction equipment that causes additional maintenance costs or equipment rental (Crespo 2015).

The present research starts from the hypothesis that implementing $5 \mathrm{~S}$ in the maintenance workshop of a road construction company will improve its efficiency, the availability of equipment and the workplace environment. So, a pilot implementation was carried out to know the effects of the $5 \mathrm{~S}$ and evaluate the operation's safety and productivity of the workshop by using indicators of road equipment maintenance and workplace environment.

5S includes five principles whose phonetics begins with "S" (Sánchez et al. 2016), Seiri, classify, eliminate unnecessary elements, Seito, order, organize each element by its function, Seiso, clean, suppress sources of dirt, Seiketsu, standardize, use visual information for the correct location of inputs and Shitsuke or continuous improvement.

Each S corresponds to a set of advantages, among the most prominent ones we can mention the improvement of establishments, optimization of processes, availability of equipment (Salem et al. 2015) and reduction of accidents. In 5S safety is an implicit of its different stages, in addition, it is not necessary to explain much the difference in risks from a messy place to a clean one, where the benefits are more than evident, in fact there are several authors who refer to the $6 \mathrm{~S}$, considering this sixth $\mathrm{S}$ as occupational safety and health or OSH (Enshassi and Zaiter 2014; Montero 2016). In other words, the incorporation of tools of the Lean Methodology allows the synergy of the processes to create various safety programs that make the worker aware of their care to prevent accidents at work (Alsamadani et al. 2013). In construction projects, the versatility of $5 \mathrm{~S}$ has reported implementation success rates of close to 50\% (Sinan and Hakan 2009). Even so, little is known about its application in other areas of the work of a construction company such as maintenance of construction equipment. 
When applying $5 \mathrm{~S}$, it is necessary to use a set of equipment and occupational safety indicators in order to measure the expected effects (Zegarra 2016), as detailed in Table 1. The key process indicators (KPIs) used in this research, their calculation formula and the meaning of each of the value ranges, were taken from bibliographic sources that are detailed below.

Table 1: Indicators of heavy equipment

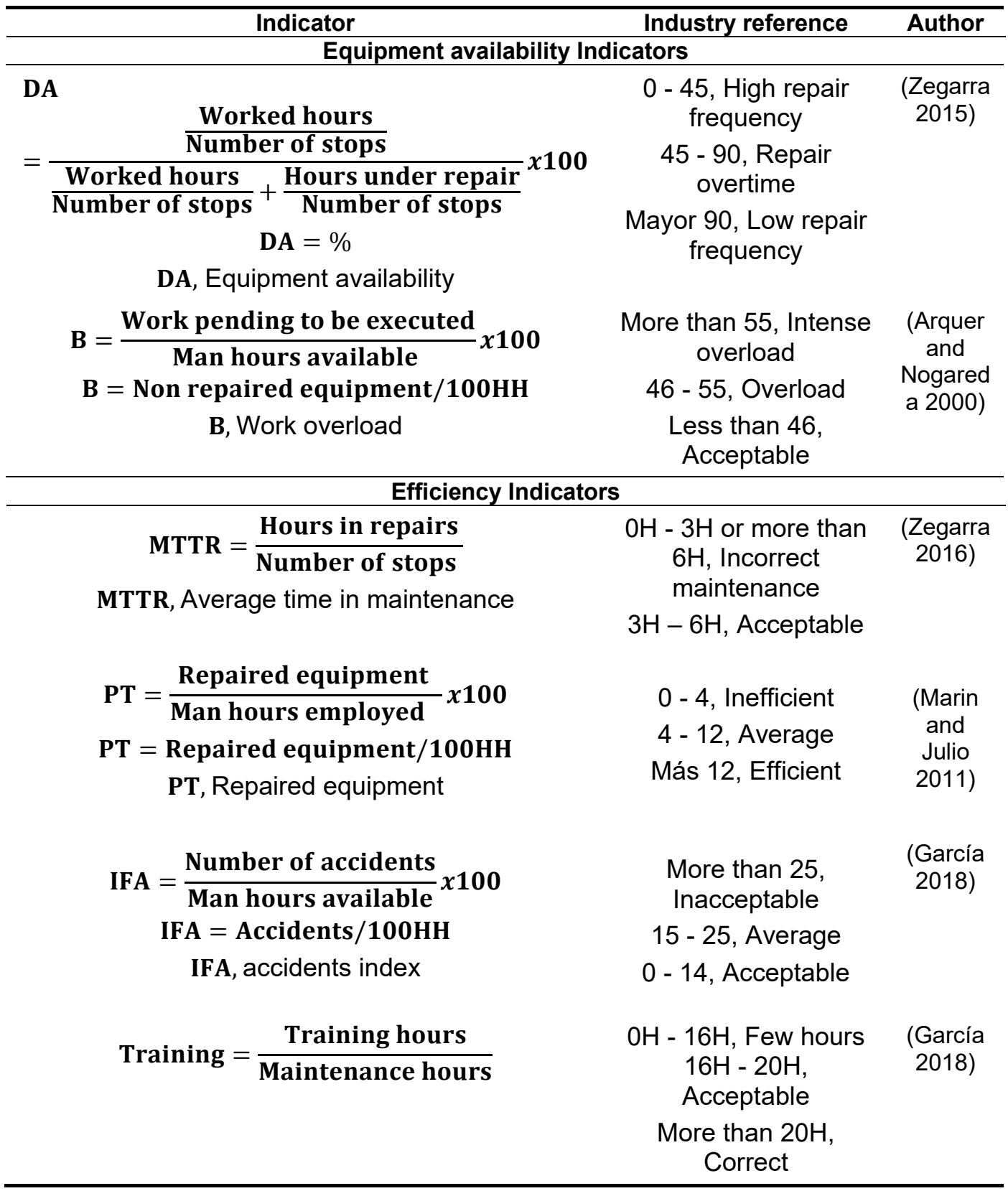

\section{S IMPLEMENTATION}

During this research, the first step was technical visits to a Toyota car maintenance workshop to learn on site (Gemba) the methodology and visual management tools that 
have allowed the company to lead 5S worldwide. Immediately, with the support of the company manager, the first meeting was held with the workshop workers. There the purposes and commitments required by the methodology for its correct execution were transmitted. Then, workers expressed interest, acceptance and initiative for the implementation of 5S, starting the collaboration of the main parties (manager and workers) to achieve the expected objectives. An opinion survey of seven questions associated with issues of order, cleanliness and maintenance processes of equipment (Appendix 1) was applied to twenty workshop's workers through a Likert perception scale (Table 2).

Table 2: Likert rating scale used

\begin{tabular}{cc}
\hline Rating & Scale Likert \\
\hline 1 & Always \\
2 & Usually \\
3 & Very often \\
4 & With some frequency \\
5 & Occasionally \\
6 & None \\
\hline
\end{tabular}

After, process developed in the maintenance workshop were analyzed to define a set of indicators that allow to measure the improvements achieved by $5 \mathrm{~S}$ implementation. Also, a KPI control panel was set in a visible place to communicate to the workers the daily results in health and safety as well as performance (Appendix 2). The calculation of each indicator was based on values collected on site using an information gathering sheet. The baseline of the group of indicators was determined measuring the initial workplace situation, the availability of equipment and efficiency of the workers, to detect critical points of the workshop management. In order to get the worker to adopt the methodology as part of their daily activities, starting the second week of implementation, the workshop chief was the one who carried out the monitoring of the indicators using the information gathering sheet and the warehouse keeper daily registered the KPI values on the board (Appendix 2).

Considering the baseline, it was defined as an implementation strategy that $5 \mathrm{~S}$ be executed in two stages. The first stage took seven weeks for the application of the first two $\mathrm{S}$ (classifying and ordering) in each of the workshop wineries, the second stage was developed in three weeks to implement $2 \mathrm{~S}$ in external areas and the continuity of the methodology (clean and standardize) all facilities were worked together. Starting the implementation of 5S, for the development of the first $\mathrm{S}$ (classifying), the facilities were recognized through a tour with the workers to obtain a photographic backup of the situation before 5S. A topographic survey of the area of each of the warehouses was carried out identifying the lack of free circulation spaces. For this $\mathrm{S}$, it was necessary to define the criteria for classifying the materials (Figure 1). For this purpose, each worker was given a classification sheet of the object that should be filled out with a checklist based on the frequency of their use.

With the objective of achieving organized areas the second $\mathrm{S}$ was implemented. During this process the spaces destined for the location of inputs were adapted, changing worn shelves for new shelves with increased divisions, obtaining a greater amount of storage spaces. The shelves were painted in different colors so that any worker can efficiently identify the location of each item, since each color corresponds to a specific group of items. Considering occupational safety, it was defined that heavy equipment and items should be placed at the bottom of the shelves. The shelves were located as islands 
to obtain free circulation areas. Also, a board with hangers was added to hang adhesive tapes, glues, etc. Finally, a specific area was defined for equipment catalogs to be placed.

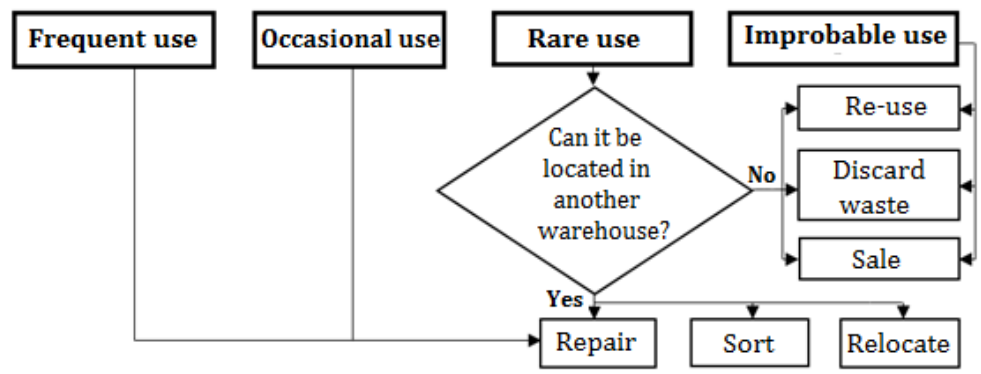

Figure 1: Classification of workplace objects

After the first stage, a meeting was held with the company manager to measure the progress of the implementation. The hiring of personnel to appoint the implementation transmitted to the personnel the commitment of the management, and aroused a greater interest on $5 \mathrm{~S}$.

Continuing with the second stage, the workers proceeded to the classification and order of the equipment located in the outdoor facilities. As for the third S, the cleaning of the waste thrown on the site was carried out. The areas with exposed soil were covered with a gravel layer, thus giving each team a clean storage space. The spare parts of equipment were ordered by size in a single place to sell them as scrap metal. Scrap pieces, oil and grease containers, equipment and scaffolding were collected to dislodge them. The equipment in bad condition was grouped in an isolated place. Measures to reduce vehicle traffic speed were placed at the entrance of the workshop to reduce the environmental dust that accumulates on parked equipment.

During the fourth S, standard procedures were defined and responsibilities of the workers were assigned in the cleaning processes of shelves, daily collection of garbage dumps, organization of work tables, use and storage of tools. Signs designed with the logo of the company and the name of the inputs were placed on the shelves, and to maintain the benefits obtained with $5 \mathrm{~S}$, educational videos were shared through the use of social networks that demonstrated the progress achieved passing from the previous to the after $5 \mathrm{~S}$ in the workshop.

The fifth $\mathrm{S}$ was difficult to achieve, despite having witnessed advances in staff commitment due to management support, a lack of continuity in the implementation of $5 \mathrm{~S}$ could be perceived in the work methodology when there are no supervisors present. It was not possible to promote self-discipline in all workshop personnel. In addition, it is known that the benefits of the fifth $\mathrm{S}$ use to be evidenced in the long term and require greater dedication and commitment from its stakeholders.

\section{RESULTS AND DISCUSSION}

The results of the opinion survey on the order, cleaning and maintenance processes died to twenty workers of the workshop are stand out in Figure 2, these results were obtained from the sum of the values of each question within the Likert scale. From the analysis of these results it can be mentioned that three workers opined that frequently the workshop is neat, clean and fulfilling efficient maintenance processes with an average value of 3.14 on the Likert scale and seventeen workers believed that with occasionally the workshop is orderly, clean, organized and comply with efficient maintenance processes, with an 
average value being of 4.62 on the Likert scale. This result confirms the need to change the conditions of work of the workshop, having been perceived by those involved, but had not been declared or assumed. This first step for change is essential to generate synergy according to Burnes (2004).

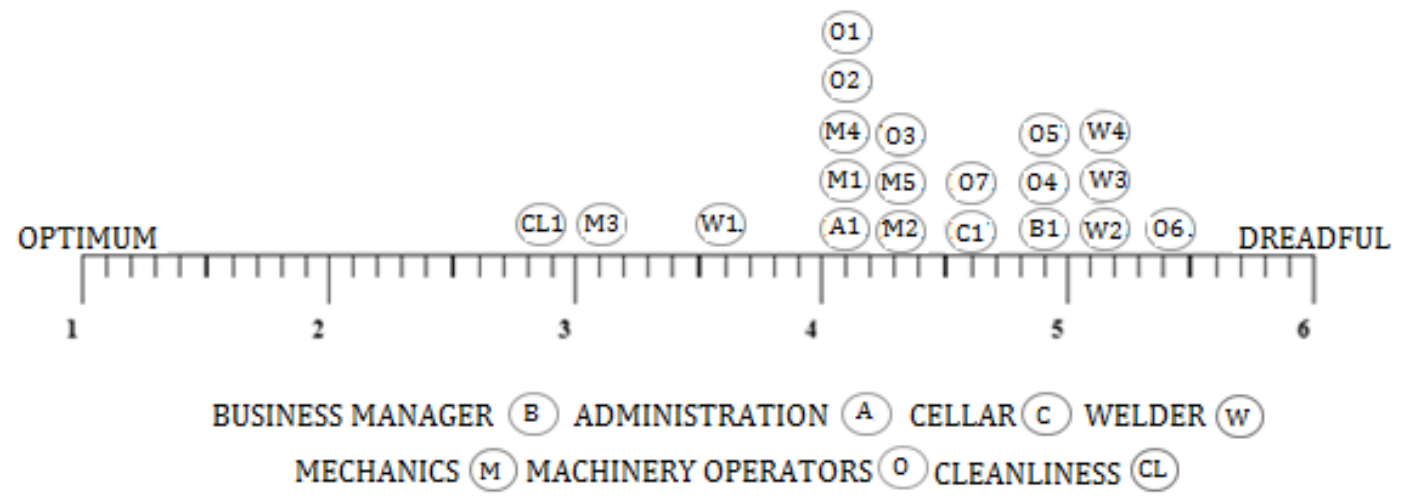

Figure 2: Worker perception of the workplace condition before $5 \mathrm{~S}$

As a result of the monitoring of the maintenance processes of equipment of the workshop, for one week (Monday to Saturday) for five hours a day, the baseline (Before 5S) of this investigation was obtained by recording the KPI values as can be observe in Figure 3. The analysis of these data is based on the evaluation criteria previously defined in Table 1. For the presentation of the indicators, their mean value was defined as the characteristic value, which is a measure of central tendency and less sensitive to the dispersion of data, making the evaluation of very high or very low indicators contribute in the same way within the baseline (Batanero 2000). To achieve efficiency in the control of indicators KPI, were programmed dashboards in Microsoft Excel, which consists of visual tools that show the value of each indicator within an acceptable or unacceptable value according to the ranges and criteria established in the Table 1 and allow the user to make decisions based on visual graphs and dynamic tables (Figures 3 and 5).

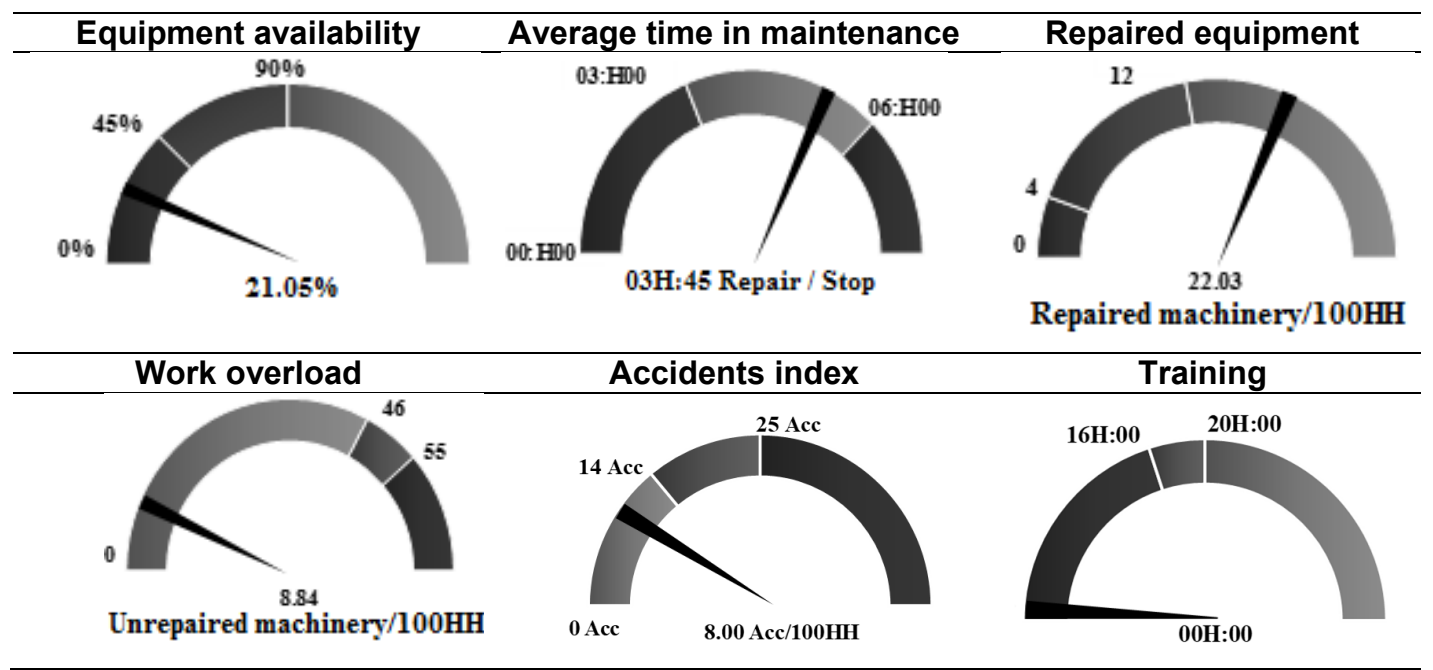

Figure 3: Dashboard KPIs before the implementation of 5s (Baseline) 
Of the baseline of this research, it can be mentioned that before implementing $5 \mathrm{~S}$ the equipment availability (21.05\%) and training hours $(00 H: 00)$ were very close to an unacceptable value, since as indicated in Table 1 its correct values are $45-90 \%$ and $16 H 00-20 H 00$ respectively, and only the characteristic values of the indicators of, repaired equipment, average time in maintenance, accident index and work overload were found within an acceptable range.

The value of the accidents index was below industry average $(8 \mathrm{Acc} / 100 \mathrm{HH})$ and it was not a wise indication of occupational health and safety to worker. Once $5 \mathrm{~S}$ is implemented, were used daily cards of acts and unsafe conditions reported, created by the research team based on the criteria established by the OHSAS-18001 Standard Health and Safety Management System that are detailed in Table 3 (OHSAS Project Group 2007), in this way, it was possible to identify that $22 \%$ of accidents occurred during the $5 \mathrm{~S}$ implementation were a type A such as lack of protective equipment, gas leaks, and even lack of knowledge in case of serious injuries of equipment operators without equipment safety or unsafe transport. The $72 \%$ corresponded to a potential for unsafe condition type $\mathrm{B}$ such as excessive noise, inadequate or obstructed storage areas and inappropriate classification of solid waste, while the remaining $6 \%$ were type $\mathrm{C}$, such as lights and equipment turned on unnecessarily, poor electrical connections, areas without emergency signaling and poor lighting.

Table 3: Potential for unsafe conditions according to OSHAs

\begin{tabular}{ccc}
\hline Class & Potential for unsafe condition \\
\hline High & A & It could result in death or disability \\
Average & B & It could result in disability or illness \\
Low & C & It could cause minor injuries \\
\hline
\end{tabular}

According to Zegarra (2015), one of the primary objectives of $5 \mathrm{~S}$ is to improve the working environment for workers, which is the reason to make topographic survey of the warehouses before the $5 \mathrm{~S}$ implementation. From values obtained and shown in Table 4 it can be established that the quality of the space in which the daily activities of the workers were carried out was deficient and inadequate due to its size or shape. Such condition affected negatively to the workshop occupants and this was the most important factor to consider when assessing the well-being of the worker due to the great impact it can have on their health and productivity.

Table 4: Circulation areas available and not available in the workshop before 5S.

\begin{tabular}{ccc}
\hline Workplace & Occupied area & Available area \\
\hline Materials warehouse & $35.40 \mathrm{~m}^{2}$ & $53.35 \mathrm{~m}^{2}$ \\
Mechanics & $24.07 \mathrm{~m}^{2}$ & $47.42 \mathrm{~m}^{2}$ \\
Parts warehouse & $68.53 \mathrm{~m}^{2}$ & $49.23 \mathrm{~m}^{2}$ \\
\hline
\end{tabular}

Once the effects generated by the implementation of $5 \mathrm{~S}$ were evident, a new survey was applied on workplace conditions and, as can be seen in Figure 4. Twenty workers considered that the workshop was in good condition, among the opinions expressed by them, the existence of clean and tidy spaces where to store each of the equipment for daily use was highlighted. Also they recognized that the creation of cleaning and organization habits was possible, which coincides with that found in most research of this effective 
and simple tool (Salem et al. 2015). Since by implementing 5S and by directly involving the worker in the methodology it becomes the fundamental entity that generates change.

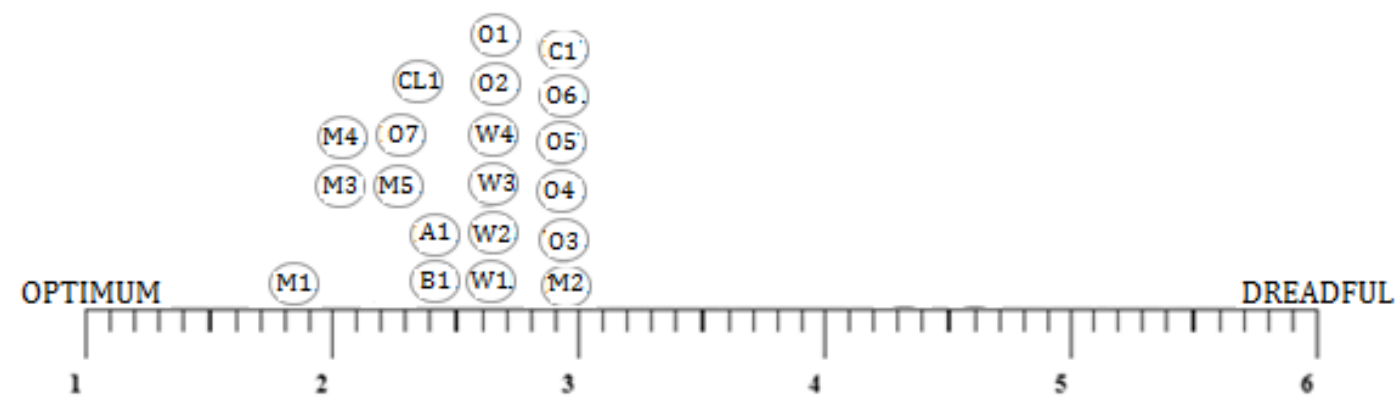

Figure 4: Worker perception of the workplace after $5 \mathrm{~S}$

As part of the methodology it must also be guaranteed that that the worker adopts the $5 \mathrm{~S}$ as part of his daily activities. So that, from the second week of implementation the mechanic chief of the workshop carried out the register of the values needed to calculate indicators by using a daily information sheet, and also, storage cellars chief filled up the KPI control panel daily; both tasks were carried out under the supervision of the research team. Showing as results the KPI values obtained after thirteen weeks of $5 \mathrm{~S}$ implementation are presented in Figure 5. Their analysis, discussion and recommendations that the research team raises are detailed below.

Equipment availability Average time in maintenance Repaired equipment

Figure 5: Dashboard KPIs after 5S implementation

According to Zegarra (2015) it is possible to achieve $90 \%$ of availability of machinery, following an adequate planning, programming and organization of the collection of a constant information flow of the state of the equipment and attend to the failures in the shortest possible time. However, in this research, the equipment availability indicator kept from that limit increasing scarcely $1.17 \%$ after implementing $5 \mathrm{~S}$, this is due to the number of stops of the machinery and the time it takes for the construction company to request a replacement of machinery from the supplying companies. Also, most of the equipment fleet have exceeded their lifetime so maintenance works occur unexpectedly 
and are much more expensive to include spare parts that are not normal replacements. In consequence maintenance work happens unexpectedly and takes long time due to the lack of spare parts for the old models. To improve this indicator, it is suggested that workers begin to develop preventive maintenance for express machinery control tasks such as greasing, lubricating and carrying out minor repairs, this will allow the workshop to move towards predictive or corrective maintenance with which maintenance costs decrease, controlling machinery replacements and thus prolonging the life of the equipment, maximizing its service and economic value.

As a logical consequence by not improving the machinery availability indicator, the indicator of average stop time was also not reduced, in the workshop, the delivery time of a repaired machinery can be either $3 H 00$ or $12 H 00$. This is due to different mechanical failures that occur in the old machinery. A high value of this indicator indicates that the damage suffered by the machinery was severe and the administrative area was slow to obtain a specific spare part and a low value indicates that the damage was less or that the maintenance work was not carried out correctly, so that the maintenance work carried out had to re-correct faults. It is recommended that the administrative staff of the workshop handle, control and constantly follow up on timely data whenever there are machinery repair problems and make improvement decisions before equipment repair work is complete.

Regarding the machinery repair indicator, this KPI remained within ranges equal to or greater than 20 Repaired Machinery/100HH, remaining within a range that exceeded the upper limit of 12 Repaired Machinery/100 H H. This is due to the fact that administrative personnel of the workshop does not monitor timely data on repairs made of the machinery. This behaviour according to Marin and Julio (2011) triggers a low or no performance control and productivity analysis of workers, which makes it impossible for them to make equipment improvement decisions without having to completely repair it.

The average value of the work overload was considerable variability since the values obtained from this indicator remained within an acceptable range of 46 unrepaired machines / $100 \mathrm{HH}$, so there is no work overload, the causes identified by the team of research is similar to explained by Arquer \& Nogareda (2000), according that the proper use of the time available to correctly handle workloads that may occur, depends above all on the performance and experience of the worker. Even so, it has been necessary to recommend that when appropriate, the company provide training, daily incentives and corresponding breaks, small contributions that help in some way to reduce the workload and show concern for the health of its employees as a priority element within the company.

The results obtained from the accident rate decreased during the $5 \mathrm{~S}$ implementation period, it is also mentioned by previous research (Enshassi and Zaiter 2014). However, it became evident a resistance of the personnel to use protective equipment. Then by manager's commandment their use was obligatory and permanent. In addition, the dissemination of general guidelines for the management of occupational risks improved the indicator.

As a result of manager's provisions, the training indicator showed considerable progress, since workers were able to contribute 4 to 5 hours per week of training in the $5 \mathrm{~S}$ methodology and in occupational safety issues but it is necessary to recommend that the construction company invest hours of training every two or three months to keep its workers updated and knowledgeable of the maintenance processes of heavy machinery, since it was evidenced several times that the machinery was operated by workers who did 
not correspond to the maintenance area, due to the lack of personnel and this in the long term damages the operation of the equipment.

It should be noted that as a collateral effect of the implementation of $5 \mathrm{~S}$, it increased the circulation areas in the workshop. In the new free areas, it was necessary to apply ergonomics principles to analyse the interaction between man, machines and work environments. In this way, the workspaces were designed although its effect in the workplace quality could not be evaluated.

Table 5: Circulation areas available and occupied in the workplace after 5S

\begin{tabular}{ccc}
\hline Workplace & Occupied area & Available area \\
\hline Materials & $23.37 \mathrm{~m}^{2}$ & $65.38 \mathrm{~m}^{2}$ \\
warehouse & & \\
Mechanics & $19.07 \mathrm{~m}^{2}$ & $52.42 \mathrm{~m}^{2}$ \\
Parts warehouse & $18.70 \mathrm{~m}^{2}$ & $99.06 \mathrm{~m}^{2}$ \\
\hline
\end{tabular}

An unexpected benefit from this intervention came from the sale of 50T of scrap metal to a local steel supplier. This waste material was collected at the beginning of the third S. The eviction of this material in stock gave the construction company an important economic income and about $700 \mathrm{~m}^{2}$ of additional space to the workshop environment to carry out heavy equipment maintenance work.

In summary, due to the first and second $\mathrm{S}$, unsafe conditions for workers were reduced. As a result of the third $\mathrm{S}$, the sources of dirt were removed. With the fourth $\mathrm{S}$, generated daily habits in the worker and compliance with cleaning lines, order and organization over the first three S. And the fifth S was not measurable, because it was not visible, and will only be shown in the long term evidenced in the behavior and culture of self-discipline of the worker (Salem et al. 2015).

All the data collected and analyzed in this maintenance workshop research are in the file of the construction company and are considered sensitive information.

\section{CONCLUSIONS}

The implementation of 5S improved the workplace environment and fostered a culture of prevention in the workshop's workers. They assumed the cleaning as an activity of autonomous and routine that increased work areas available for equipment maintenance. Also, 5S improved the image with the clients and suppliers and generated responsibility with the workshop's performance increase. $5 \mathrm{~S}$ further improved the accident rate indicators, training hours, average downtime, repaired equipment and work overload. Thus, the hypothesis proposed for this research was partially tested since the $5 \mathrm{~S}$ implementation improved the safety of the workshop. However, the hypothesis was not fulfilled regarding the availability of equipment, since its improvement also require an important commitment from the company for the renewal of their equipment fleet, that will allow a preventive maintenance plan to be generated and propitiate availability control of equipment for road works. An improvement of the indicators applied in this research depends, beyond the implementation of 5S, on an improvement in the company management practices of the workshop. Also, the management of its suppliers and the replacement of equipment that have fulfilled their lifetime.

The results suggest that $5 \mathrm{~S}$, among other factors, favor the occupational safety and health of the workers. 5S improved the workshop facilities and standardized order and cleaning processes, that facilitated advise, training, controlling and improvement of the 
site conditions avoiding failures in use and organization of tools, supplies and equipment thus preventing accidents due to their misuse.

This research was limited to studying the effects of $5 \mathrm{~S}$ in a single workshop of the road construction company. The results shown are encouraging, however, they are not generalizable or extended to other workshops or companies.

\section{ACKNOWLEDGMENT}

The research team thanks to COVIPAL CIA. LTDA. construction company for supporting this $5 \mathrm{~S}$ implementation and research.

\section{REFERENCES}

Alsamadani, R., Hallowell, M. and Javernick-Will, A.N. (2013). "Measuring and modelling safety communication in small work crews in the US using social network analysis." Construction Management and Economics, 31(6), 568-579.

Arquer, I. and Nogareda, C. (2000). Carga física y mental de trabajo: Indicadores. (Physical and mental workload: Indicators), Ministerio de trabajo y asuntos sociales (Ministry of labor and social affairs), 1-6.

Batanero, C. (2000). "Significado y comprensión de las medidas de posición central." (Meaning and understanding of central position measurements.) Didáctica de la metemática (Teaching of mathematics), 25, 41-58.

Boatswain, M. (2016). Embrace Change to Keep up with the global construction industry. Burnes, B. (2004). "Kurt Lewin and the Planned Approach to Change:A Re-appraisal." J. Management Studies, 41(6), 977-1002.

Crespo, W. (2015). "Mejora de la productividad en la construcción de edificaciones en la ciudad de Quito, aplicando Lean Construcction." (Improvement of productivity in the construction of buildings in the city of Quito, applying Lean Construction), Central Univ. of Ecuador, Quito, Pichincha, Ecuador.

Enshassi, A., and Zaiter, M. A. (2014). "Implementation of lean tools on safety in construction projects in palestina." Proc. 22 $2^{\text {nd }}$ Ann. Conf. Int. Group for Lean Construction, Oslo, Norway, 1205-1218.

Marin, G., and Julio, S. (2011). "Cálculo de indicadores productivos." (Calculation of productive indicators), Institucional de la Univ. Politècnica de València, Institutional of the Polytechnic University of Valencia, Camí de Vera, Valencia, Spain.

Montero, R. (2016). "Relación entre el Lean Manufacturing y la seguridad y salud ocupacional." (Relationship between Lean Manufacturing and occupational health and safety), Autonomous Univ. of Occident, Colombia, 24(2), 1-6.

OHSAS Project Group. (2007). Ohsas (Occupational Health and Safety Assessment Series), British Standards Institution (BSI), United Kingdom, London, 18001:2007.

Pestana, C., and Gambatese, J. (2016). "Lean Practices and Safety Performance." ASCE $J$. of Management in Engineering, 1710-1719.

Porras, H., Sánchez, O., and Galvis, J. (2014). "Lean Construction philosophy for the management of construction projects : a current review." AVANCES Investigación en Ingeniería, 11(1), 32-53.

Salem, O., Solomon, J., Genaidy, A., and Luegring, M. (2015). "Site implementation and assessment of Lean Construction Techniques." Lean Construction, 2(2), 1-59.

Sánchez, A., Moya, C., and González, R. (2016). ¿Cómo influye el método de las 5S en la gestión de proyectos de las empresas?" (How to influence the $5 \mathrm{~S}$ method in the 
project management of companies?)

Sinan, K., and Hakan, E. (2009). "Resistance to Change." Baltic Business School, 1-90. Sowards, D. (2012). Lean Construction Pocket Guide. MiniBuk, Mesa, AZ.

Zegarra, M. (2015). "Modern Heavy Equipment Maintenance Management." Ciencia y desarrollo de la Universidad Alas Peruanas, 18(1), 57-67.

Zegarra, M. (2016). "Indicators for heavy equipment maintenance management." Revistas UAP EDU, 19(1), 25-37.

\section{APPENDICES}

\section{APPENDIX 1: OPINION SURVEY CARRIED OUT TO WORKERS}

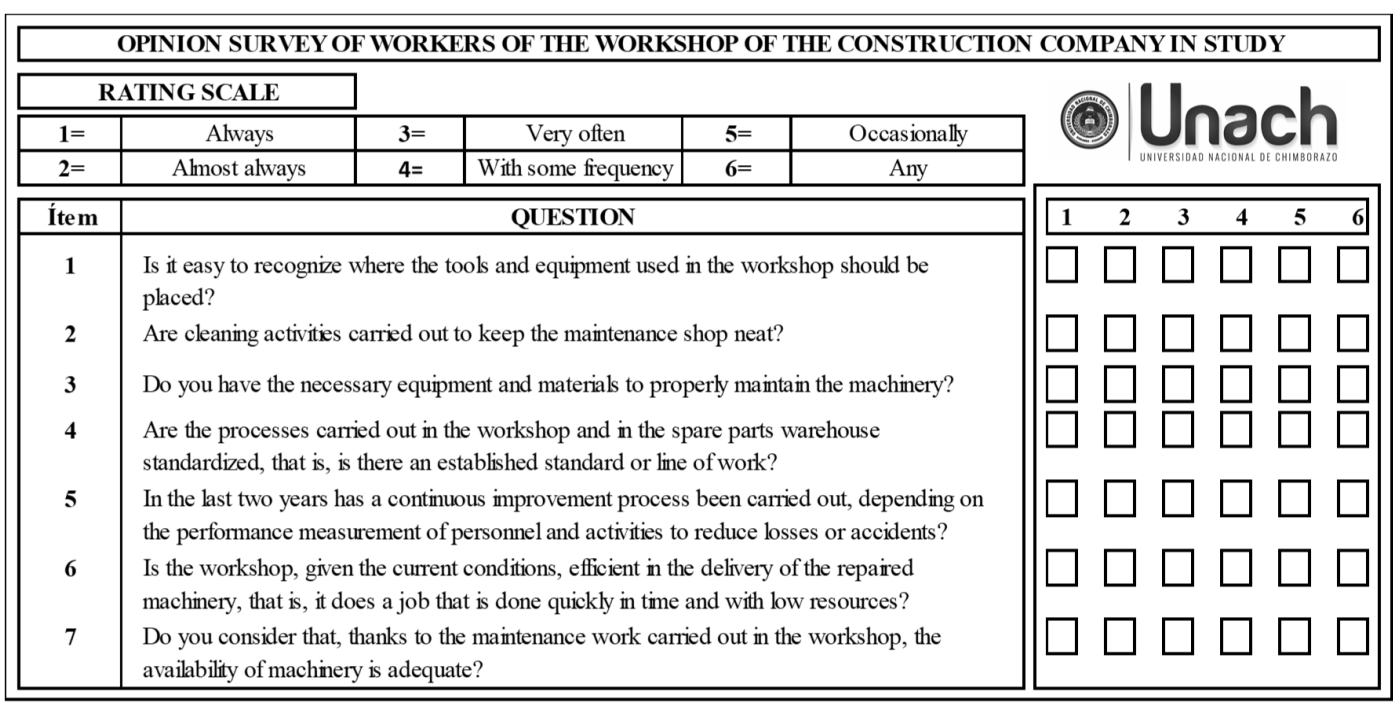

\section{APPENDIX 2: INVOLVEMENT OF THE CREW IN 5S IMPLEMENTATION}

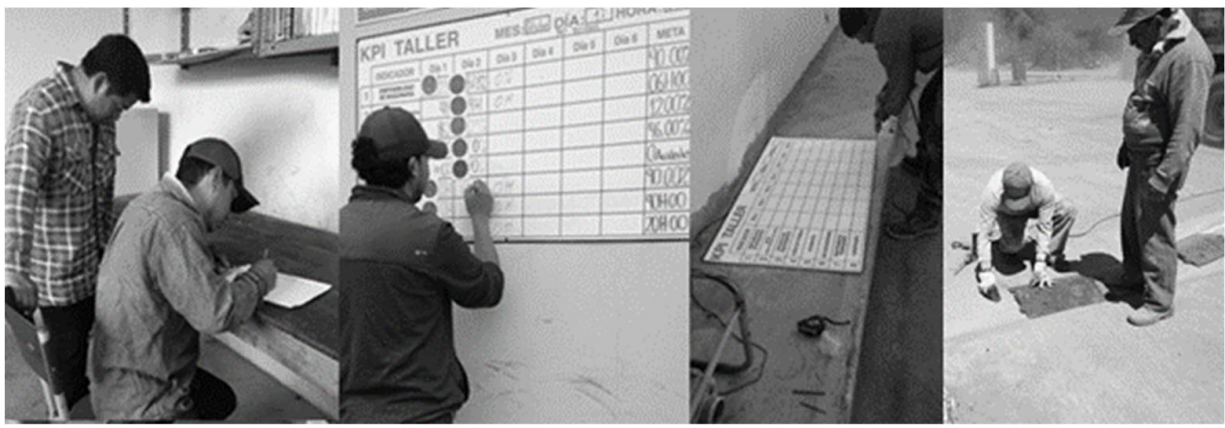

\section{APPENDIX 3: WORKPLACE CONDITIONS BEFORE AND AFTER 5S}

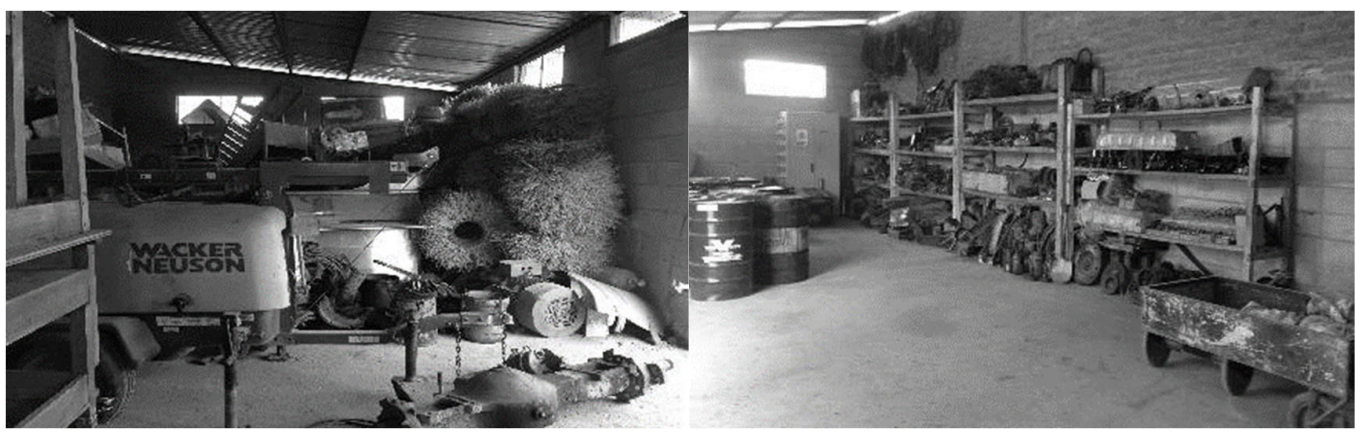

